\title{
Living Arrangements and Conditions of Older Persons in Namibia
}

\author{
Nelago Indongo*, Naftal Sakaria \\ Multidisciplinary Research Centre, Windhoek, Namibia \\ Email: "nkanime@unam.na
}

How to cite this paper: Indongo, N. and Sakaria, N. (2016) Living Arrangements and Conditions of Older Persons in Namibia. Advances in Aging Research, 5, 97-109. http://dx.doi.org/10.4236/aar.2016.55010

Received: June 17, 2016

Accepted: August 18, 2016

Published: August 22, 2016

Copyright $\odot 2016$ by authors and Scientific Research Publishing Inc. This work is licensed under the Creative Commons Attribution International License (CC BY 4.0).

http://creativecommons.org/licenses/by/4.0/

\section{(c) (i) Open Access}

\begin{abstract}
In Africa, ageing is a phenomenon that is just beginning to reveal its shape. Most governments, including the Namibian government, recognize the fact that the number of older persons is on the increase, however, discussing it is still a distant phenomenon and family matter. This paper examines the living arrangements of older adults in Namibia, identifying the existing structure of living arrangements and the nature of family relationships of older people, as well as provides some basic descriptive information on the housing conditions in which older persons live and how they are associated with their socioeconomic and demographic factors. The analysis is based on 1991, 2001 and 2011 Namibia Population and Housing Censuses. The study concluded that living arrangements is constantly changing from extended family pattern to western nuclear family, mainly due to urbanization and decreased fertility rate. Housing conditions had notably improved in rural areas while in urban areas the conditions are affected by the mushrooming of informal settlements. There is need to encourage or conduct focused research on ageing to help coin policies based on evidence and make communities sensitive towards ageing. The study further recommends Government to encourage old people to form organizations that would in turn focus on sensitizing and help championing issues of ageing and aged persons.
\end{abstract}

\section{Keywords}

Ageing, Living Arrangements, Living Conditions, Older Persons, Namibia

\section{Introduction}

The world's population is ageing and presents major policy issues in the developing world. Issues concerning household structure and support for older persons in developing countries are becoming increasingly important as population ageing begin to in- 
fluence many of these societies. In Africa, ageing is a phenomenon that is just beginning to reveal its shape; at present, it is a family concern. Although sub-Saharan Africa's older population is not as large in size as in other regions of the world, it must still be considered as a potential cause for concern since Africa is ageing at a time when its resources are being depleted [1]. There are indeed considerable differences in African living conditions depending on the level of development and the degree of urbanization, modernization and other developmental process that impact on living conditions. The decline in fertility rates is seen as one of the contributing factors to increases of older persons in most African countries [2]. In most developing countries, a majority of older persons live with relatives, most commonly with their own children.

Multigenerational households traditionally have provided the main social context for the sharing of family resources and the provision of mutual support as needs arise over the life course. In developing countries it is common for at least one adult child to stay with parents as long as they are alive. However, in recent years the proportion of older persons living alone has risen in many countries and the proportion residing with children has declined. Traditionally elder people are viewed as the most influential persons in society when it comes to conflict solving and almost everyone look upon them for guidance in ones every day's lives. In the past, older persons could depend on their families for support, however the society is transforming from tradition-bound multi-generational families to more modern nuclear families through the process of development, and this compelled elderly persons to be left with either no or little support [3]. The development process worsens the deficiencies of the safety net as productive youth migrate to urban areas for better opportunities, leaving elderly and their compulsions to them behind. Modernization has brought vast of changes, whereby family sources of income shifted from traditional sources to the markets, with declining capability of elder people to feed their family [4].

Although coresidence with an adult child is no doubt critical for support of older adults in sub-Saharan Africa, living with grandchildren is also likely to be important living arrangements. The tradition in Africa is to live with extended families. Child fostering is a practice common in Africa where many children spend substantial portions of their childhood away from their parents. In many African societies, grandparents are the most common recipients of foster children [5] [6]. It is a norm in developing countries that living arrangements are fundamental determinants of wellbeing. The aged tend to require support for functional tasks such as cooking and shopping as well as material and psychological support to ensure their survival, particularly when they no longer work for pay and begin to suffer from ailments that limits their ability to carry out tasks necessary for daily survival. In sub-Saharan Africa, the family tends to be cornerstone of social support.

Earlier research [7] reported that there are several socio-economic characteristics that play an important role in the choice of living arrangements among older people. They indicated that higher levels of education and financial resources tend to increase the likelihood of residential independence among older people. Another research [8] 
has also suggested that increased income promotes independent living since privacy and autonomy, both of which are highly valued, can be achieved with adequate financial means.

Demographic, socio-economic and cultural factors have all been advanced as important determinants of residence patterns. It was reported that the trend toward greater residential independence among older people reflects, to a large extent, positive developments. For example, recent improvements in male longevity have meant that older women are more likely to remain living with a spouse in later life. Additionally, declines in disability at older ages shown in some studies may have led to greater residential independence [7].

Mortality and fertility decline that move population through their demographic transition inevitably result in increase over time in the proportion of a population who are old. In industrialized countries the proportion of age $65+$ is projected to double by 2020 , while in much of the developing world population ageing is less pronounced because the transition to low levels of fertility and mortality is still underway. Population ageing in many developing countries is occurring at times when such countries are also experiencing rapid socio-economic demographic changes. Economics are growing as industry replace agriculture, literacy level rise, urbanization proceeds rapids women bear fewer children and people live longer and healthier lives. The effects of these trends on families, household kin networks and subsequent support from older persons are complex and not well documented. Researchers [2] [9] argued that in largely rural traditional societies, residential families are more often extended in modern industrialized societies, where the independent nuclear family is predominant.

This paper examines the living arrangements of older adults in Namibia, identifying the existing structure of living arrangements and the nature of family relationships of older people. The study aims to provide some basic descriptive information on the types of households in which older person live and examining how living arrangements are associated with socioeconomic and demographic factors of older persons. Research [10], emphasized that care for the elderly is posited in the Namibian Constitution as one way of alleviating negligence, abuse and socioeconomic factors. The section on fundamental rights in the Constitution includes the following, which are relevant to the elderly-caregiver relationship: the protection of life-providing safe quality care; the protection of liberty and respect for human dignity, equality and freedom from discrimination. It is also worth mentioning that in Namibia, old age homes are not popular in most regions. They are mainly found in Windhoek city and other towns like Rehoboth and Coastal towns, but rare or non-existing in the northern or north eastern regions where more than $50 \%$ of older population reside.

\section{Materials and Methods}

The paper uses data from 1991, 2001 and 2011 Namibia Population and Housing Census. For each household member, the household questionnaire records age, sex, relationship to head, education level, marital status and residential status. In addition, cha- 
racteristics of the household i.e. source of drinking water, source of energy, type of toilet facility, household possession are recorded. The study focuses on analyzing older persons aged 60 years and above and assesses the trend of living arrangement and conditions since independence. The three Census datasets were obtained from Namibia Statistics Agency with information of persons aged 60 and above linked with their household characteristics. The interest was on analyzing older person who live in conventional households. Indicators for analysis include headship, relationships and co residence with spouse, children and others. Unweighted regional averages and regressions are used to determine whether variations exist. The logistic regression analysis was performed to assess whether households that are headed by older persons are associated with certain socio-economic, demographic and household characteristics. The dependent variable was constructed to constitute two groups, coded 1 for all older persons who are head of households and 0 otherwise.

\section{Results}

Overall, the 2011 population and housing census showed that $7.1 \%$ of Namibian population living in conventional household were older persons. It is noted that the proportion of older persons has remained somehow constantat $7.1 \%$ since independence, however the average age of older persons has steadily increased from 70 years in 1991 to 72 years in 2011 for both males and females and the results show that the proportion of female older persons remains higher than for older males over the years. Although majority of the population of older persons reside in rural areas as compared to urban areas, there is evidence that this proportion has increased over time in the urban areas from $17.3 \%$ in 1991 to $21.3 \%$ in 2001 and $23.0 \%$ in 2011.The results also shows that most rural dominated regions i.e. Omusati, Ohangwena, Kavango and Oshikoto have the highest population of older persons (Table 1).

\subsection{Living Arrangements}

Overall, the majority of older persons in Namibia indicated that they are head of households. In 1991, 81.4\% of male older persons aged 60 year and above were head of households. This proportion reduced to $75.5 \%$ in 2001 and then up to $80.9 \%$ in 2011 (Table 2). The majority of women older person who reported that they are head of households were widowed (54.1\% in 1991, $45.0 \%$ in 2001 and $42.8 \%$ in 2011). There is however a decreasing trend to this effect. This could be attributed to the fact that with increasing improvements in social welfare, older males live longer resulting in decreasing mortality. The other reason could be remarriage or when the partner dies the woman is taken by other relatives to be taken care in another household. This practice rarely happens in the case of men.

The results also show that $15.5 \%$ of older persons were cared for by other relatives while $9.2 \%$ were under the care of their sons or daughters according to the 2001 population and housing census. These proportions have significantly reduced in 2011. Several factors could have contributed to this reduction. For example, the impact of urba- 
Table 1. Description of older persons by their background information and population and housing census year.

\begin{tabular}{|c|c|c|c|}
\hline & 1991 & 2001 & 2011 \\
\hline \multicolumn{4}{|l|}{ Mean Age } \\
\hline Male & 70.1 & 71.3 & 71.4 \\
\hline Females & 70.0 & 70.7 & 72.9 \\
\hline$\%$ Persons aged $60+$ & 70.3 & 71.8 & 72.3 \\
\hline$\%$ Male & 43.8 & 45.9 & 40.9 \\
\hline$\%$ Female & 56.2 & 54.1 & 59.1 \\
\hline \multicolumn{4}{|l|}{ Place of residence } \\
\hline Urban & 17.3 & 21.3 & 23.0 \\
\hline Rural & 82.7 & 78.7 & 77.0 \\
\hline \multicolumn{4}{|l|}{ Region } \\
\hline Zambezi & - & 3.1 & 3.7 \\
\hline Erongo & - & 5.4 & 5.5 \\
\hline Hardap & - & 4.0 & 4.1 \\
\hline Karas & - & 3.1 & 3.1 \\
\hline Kavango & - & 10.3 & 10.5 \\
\hline Khomas & - & 7.8 & 8.2 \\
\hline Kunene & - & 4.8 & 4.0 \\
\hline Ohangwena & - & 15.8 & 15.3 \\
\hline Omaheke & - & 3.9 & 3.2 \\
\hline Omusati & - & 17.1 & 17.7 \\
\hline Oshana & - & 8.5 & 8.9 \\
\hline Oshikoto & - & 10.0 & 10.4 \\
\hline Otjozondjupa & - & 6.0 & 5.4 \\
\hline
\end{tabular}

Table 2. Percentage distribution of older person by their relationship to head of household.

\begin{tabular}{cccc}
\hline & 1991 & 2001 & 2011 \\
\hline Head & 65.9 & 53.2 & 67.0 \\
Spouse & 14.5 & 14.1 & 15.0 \\
Son/daughter & 0.6 & 4.1 & 1.0 \\
Grandchild & 0 & 2.5 & 0.0 \\
Spouse of child & 0.1 & 1.0 & 0.1 \\
Parent of Head/Spouse & 6.6 & 7.8 & 7.1 \\
Other relative & 9.0 & 12.8 & 8.2 \\
Non relative & 3.3 & 3.8 & 1.4 \\
Domestic worker & 0.1 & 0.7 & 0.0 \\
\hline
\end{tabular}


nization which had led to more employments or education opportunities among kin members who were expected to look after these older persons could be a contributing factor. It could also be because the sons/daughters of these older persons have settled in the urban areas, and thus not able to live with their parents. Movement of population to urban areas has led to large number of older men and women left to look after themselves in the rural areas, while the young generation lives in the cities for livelihood. This has led to less availability of caregivers for older people. Additionally, the results also revealed that $3.6 \%$ of older persons were still living with their biological parents according to the 2001 census however, this reduced to $1 \%$ in 2011.

One of the notable declining changes in the living arrangements of older person is the norm of living with grandchild. With the decline in fertility rate, couples give birth to fewer children compared to the past and it makes it difficult for parent to send their children to be looked after elsewhere. As a consequence, most couple adopted a western culture of nuclear family and use education opportunities for their children as a priority. In 1991 after independence when the first Population and Housing Census was conducted, the TFR stood at 6.1 . During that time more than $60 \%$ of the population lived in rural areas and most families practices traditional ways of living. Extended family and relative ties were strong and since couples had on average more than 6 children they would send some to be looked after by extended families. Before independence in 1990 , access to education and health services was also restricted and a high proportion of the population had not attained high levels of education. For treatment, some relied on traditional ways and this put the majority at risk of dying. The life expectancy was also low compared to the current one. With improvement in services and improved access, a high number of young people migrated to urban areas in search of these services and for employment opportunities. This movement put older people at risk of living alone and vulnerable in term of care as there are few on no young people to look after them.

\subsection{Older Persons and Disability}

Population ageing is a global phenomenon affecting both developed and developing countries. It has several implications on the population. First, it is accompanied by a rise in the percentage of older persons and an increase in the prevalence of NCDs non-communicable diseases [11]. They further explained that an increase in the prevalence of NCDs contributes to a double burden of diseases for older people in Africa who simultaneously suffer from tropical diseases as well and further reported that the increasing prevalence of disability among older persons is increasingly becoming an important dimension for research in developing countries.

Disability is defined as "the negative aspects of the interaction between an individual (with a health condition) and that individual's contextual factors (personal and environmental factors)". Interactions include impairments (affecting the body), activity limitations (affecting actions), and participation restrictions (affecting experience of life). It implies having "difficulties with activities of daily living (ADL), difficulties with in- 
strumental activities of daily living (IADL), and mobility limitations" [11].

Broadly, disability affects health and wellbeing of older people. It impacts on physical functioning, leads to social exclusion and limits access to healthcare among older people. In Namibia, $16.4 \%$ of older persons reported that they have some form of disability according to 2011 Population and Housing Census. There is no difference on disability status between male and females, however the proportion of older person with disability increases with increasing age, with $24.5 \%$ of those aged $85+$ reported some form of disability compared to only $11.4 \%$ of those aged $60-64$. This is contrary to what has been reported in other studies. A cohort study in Malawi indicated that older women were more likely to be disabled than older men [12]. Even among HIV infected populations in South Africa, older women were still at a higher risk of disabilities compared to older men [13]. Studies in middle income countries have also reported increased disability among older women [14] [15]. In developed countries like USA, older women were also disadvantaged in terms of the prevalence of disability [16]. The 2011 Namibia Population and Housing census revealed that the most commonly reported disability among both males and females were blindness and visual impaired. The types of disability as recorded during the population and housing census were grouped to form the following disability groups: seeing (which includes blindness and visual impairment); hearing (deafness and hearing difficulties); communication (mute and dumbness); movement (physical impairment of upper and/or lower limbs), mental and others (albinism, autism and others). However, it is important to note some improvement (reduction) in the proportion of older persons with difficulties in seeing and moving (Table 3). But there is a concern on the increasing proportion of older persons with mental disability, from $1.7 \%$ in 2001 to $5.1 \%$ in 2011.

\subsection{Housing Conditions}

The labour policy in Namibia allows an individual to work up the age of 60 and most individuals go on retirement afterwards. Furthermore the housing loan contract is usually paid up within the maximum period of 20 years in an effort to discourage house owners to carry over bonds to retirement. The analysis of older persons indicates that in 2001 , about $77 \%$ lived in households without paying mortgage and only $11.3 \%$ were still living in household with mortgage. The proportion differs between rural and ur-

Table 3. Percentage of older persons aged 60 and above with disability.

\begin{tabular}{ccc}
\hline & 2001 & 2011 \\
\hline Seeing & 49.3 & 47.7 \\
Hearing & 10.9 & 12.1 \\
Communication & 3.4 & 3.4 \\
Movement & 31.0 & 26.7 \\
Mental & 1.7 & 5.1 \\
Others & 3.6 & 5.0 \\
\hline
\end{tabular}


ban, with $84.3 \%$ of the older person in rural area lived in households without paying mortgage compared to only $45 \%$ in urban areas. On the other hand about $32 \%$ of older persons in urban areas lived in households with mortgage. The pattern changed in 2011, with a decreased proportion of older persons with mortgage in urban areas at $15.3 \%$.

Hygienic sanitation facilities are crucial for public health. In 2010, the UN General Assembly recognized access to safe and clean drinking-water and sanitation as a human right, and called for international efforts to help countries to provide safe, clean, accessible and affordable drinking-water and sanitation. Benefits of improved sanitation are well documented and appreciated. Access to improved sanitation is one of the basic needs of people. In the year 2009 only $13 \%$ of the rural and $61 \%$ of the urban population in Namibia had access to improved sanitation services [17]. It is estimated that about $80 \%$ of people living in Namibia's rural areas and $15.7 \%$ of the urban population do not have access to sanitation at all and practice therefore open defecation [17]. The lack of basic sanitation services is one of the biggest problems which constrain the living conditions and health of many people in Namibia. In order to improve their quality of life and well-being, to promote the conservation of water resources and prevent pollution, and to stimulate economic development, the Ministry of Agriculture found it reasonable to implement dry sanitation systems on a large scale in Namibia [18]. Furthermore, the national sanitation strategy has been developed with the purpose of improving the quality of life and as key to healthy communities. Overall, only $20 \%$ of the older person lived in households that have access to flushed toilet according to the 2001 population and housing census. The majority (67.8\%) reported no toilet or either using bush as ablution facility. The proportion of those using bush was much higher in rural area with $81.3 \%$, compared to $13 \%$ in urban areas. The situation somehow improves in 2011, with $34.4 \%$ of older persons having access to flushed toiles. The improvement was more notably in rural areas where more older persons lived in households with flushed toiled and the proportion of those using bush or having no toiled had significantly reduced from $81.3 \%$ in 2001 to $56.3 \%$ in 2011 (Table 4). However, the proportion of older persons who lived in households with no toilet facility in urban areas had increased. This could be a reflection that older persons in urban areas live in informal settlements.

With regard to access to safe water, although use of piped water was prevalent there is evidence of increased use of water from boreholes and other sources in urban areas. Access to electricity as a source of energy for cooking and lighting has also significantly improved in rural areas. In 2001, only $2.2 \%$ of older persons lived in household that used electricity for cooking, this proportion increased to $24.5 \%$ in 2011 (Table 4). In urban areas, the proportion of households using electricity for cooking has decreased from $57.8 \%$ in 2001 to $31.4 \%$ in 2011 . Most households in urban areas use gas and other source of energy for cooking. A similar pattern was observed with regard to source of energy for lighting, with an increased proportion of older persons in rural areas using electricity for lighting in 2011 compared to 2001 (Table 4). This could be as a result of rural electrification. 
Access to information is a fundamental human right. According to the 2001 and 2011 population and housing Census, more than $70 \%$ of the older persons lived in a household that has a radio. The results further indicated that access to TV is only prevalent in urban areas.

Results from regression analysis show that headship of household among older persons in associated with place of residence, marital status, age and sex. Overall, male and females in rural area are more likely to be head of households than those in urban areas. Males who are in union (living as married) are 6.5 times more likely to be head of households while the odds of married females to be head of households is 0.23 . The results also show that female who are aged 90 years and older are less likely to be head of households. As reported earlier, they are likely to be living with other family members. Overall, males are also likely to be head of households that have access to electricity.

Table 4. Percentage distributions of housing conditions where older persons live by population and housing census year.

\begin{tabular}{|c|c|c|c|c|c|c|}
\hline & \multicolumn{3}{|c|}{2001} & \multicolumn{3}{|c|}{2011} \\
\hline & Overall & Rural & Urban & Overall & Urban & Rural \\
\hline \multicolumn{7}{|l|}{ Tenure } \\
\hline Without Mortgage & 76.7 & 84.3 & 45.5 & 59.2 & 54.1 & 62.5 \\
\hline With Mortgage & 11.3 & 6.3 & 31.7 & 12.6 & 15.3 & 10.7 \\
\hline Other & 12.1 & 9.5 & 22.7 & 28.2 & 30.6 & 26.7 \\
\hline \multicolumn{7}{|l|}{ Type of toilet facility } \\
\hline Flushed Toilet & 20.1 & 6.3 & 76.6 & 34.4 & 40.0 & 30.8 \\
\hline Bush/No toilet & 67.8 & 81.3 & 13.0 & 53.5 & 49.2 & 56.3 \\
\hline Others & 12.1 & 12.4 & 10.5 & 12.1 & 10.8 & 13.0 \\
\hline \multicolumn{7}{|l|}{ Water source } \\
\hline Piped Water & 73.1 & 67.0 & 98.0 & 66.1 & 68.5 & 64.6 \\
\hline Others & 26.8 & 33.0 & 2.0 & 33.9 & 31.9 & 35.4 \\
\hline \multicolumn{7}{|l|}{ Energy for cooking } \\
\hline Electricity & 13.2 & 2.2 & 57.8 & 27.2 & 31.4 & 24.5 \\
\hline Others & 86.8 & 97.8 & 42.1 & 72.8 & 68.6 & 75.5 \\
\hline \multicolumn{7}{|l|}{ Energy for lighting } \\
\hline Electricity & 19.0 & 6.1 & 71.8 & 40.1 & 41.6 & 39.1 \\
\hline Others & 81.0 & 93.9 & 28.3 & 59.9 & 58.4 & 60.9 \\
\hline Access to Radio & 79.1 & 86.9 & 77.3 & 73.0 & 79.9 & 71.0 \\
\hline Access to TV & 24.3 & 13.3 & 70.7 & 23.4 & 70.0 & 9.5 \\
\hline Access to phone & 27.4 & 17.9 & 66.1 & 44.6 & 62.2 & 39.4 \\
\hline
\end{tabular}




\section{Discussion}

In this paper we focused on conceptualizing the living arrangements and conditions of Namibian older people. We argued that it important to analyse their living arrangement and housing conditions because it would help in identifying the existing social support and the nature of family relation as well as their wellbeing. An interesting finding in this paper is that older people in Namibia coreside with other family members despite the majority of them being head of households. This result is in line with a number of studies that indicated that the majority of older people in developing countries live with their children. This pattern is slowly changing though, especially with increased urbanization and influence of western culture of encouraging nuclear family. These studies also suggest that older people living arrangements are determined by cultural norms that define family types. For example, data specific to South Africa regarding the living conditions and life circumstance of those South African aged 65 and above show that the living arrangement and therefore living condition follows the life pattern of the different racial groups of people in South Africa. Therefore, race, gender and place of residence remain the most distinguishing features of the society revealing past colonial practices. With the exception of race, headship of households in Namibia among older persons is associated with marital status, residence, and age. In Namibia it was found that above $70 \%$ of older person aged 60 and above live in rural areas. The results revealed that only $5.7 \%$ of older males reported being widowed in 2011, whereas $39 \%$ of older females reported that they were widowed. In Kenya the corresponding proportion were $7 \%$ of men and $50 \%$ of women who were widows. This is an indication that although older men had lost their wives at some point in live, these men might have remarried and hence did not consider themselves as widowed.

Disability is also prevalent among older people in Namibia. The proportion is higher among the oldest ones, aged 85 and above. The most common recorded disability is blindness and visual impairment, however it had showed some improvement according to the recent Census. The prevalence of disabilities is estimated to be highest in sub-Saharan Africa, however, it has not been systematically investigated. Many of the studies had covered smaller communities. For instance, in Tanzania, a community based study estimated disability among older people at 6\% [19]. However, the estimate was based on Hai area only. A study in north western Ethiopia on the general population reported disability at $4 \%$ [20]. But this covered about three towns in Ethiopia. The first national survey of persons with disabilities, probably in sub-Saharan Africa, was conducted in Kenya in 2007 where the survey reported that $5 \%$ of Kenyans were disabled [11]. Marital status has significant association with disability. For example, in South Africa, older people who were single were more likely to report disability compared to those who were married while older people who are divorced or separated were more likely to report disability in Uganda. Residence has been associated with disability among older people. Urban residence has been found to reduce the risk of disabilities among older people. However, in Uganda, rural older people had reduced odds of disabilities [11]. Education level of older people is also associated with disability. 
The proportion of older persons with disability was found to be higher among those who had only completed primary education compared to those with higher levels of education. The main concern in Namibia is the increasing pattern of mental disability among older persons.

Overall, the housing conditions of households, especially in rural areas, where older persons live have significantly improved. There are evidence of more households having access to safe water, improved sanitation and access to electricity. In urban areas, the housing conditions are worsened by the mushrooming of informal settlements and this had deteriorated the access to basic needs like toilet facilities, water and electricity supply.

\section{Conclusions}

It is evident that with social and economic development, the Namibian population is slowly ageing and this population is expected to increase by the next population and housing census planned in 2021. The study also concluded that living arrangements is constantly changing from extended family pattern to western nuclear family, mainly due to urbanization and decreased fertility rate. Safe drinking water and adequate sanitation are crucial for poverty reduction, and for sustainable development and need to be put on priority agenda. There is also need to improve proper sanitation in urban areas especially taking into account the mushrooming of informal settlements.

Although the Namibian government recognizes the fact that the number of older persons is on the increase, discussing ageing is still a distant phenomenon and family matter. Society is also cognizant of the fact that the aged people are faced with numerous challenges which are both social and economic; older persons face among other problems the inability to care for themselves, abandonment and destitution, humiliation because of being old. Apart from government providing for pension grant and medical cover for elderly, there seems to be no information on the existence of policies, social programs and plans addressing issues of the aged persons. In order to make known the importance of ageing and the likely effects if left unattended, there is need to encourage or conduct focused research on ageing; this has a potential to help coin policies based on evidence and would make many communities sensitive towards ageing. It is also important for Government to encourage old people to form organizations that would in turn focus on sensitizing and help championing issues of ageing and aged persons. Older people should give their recommendations of initiatives through regional and local government platforms for them to be communicated to relevant Government Offices.

\section{References}

[1] Apt, N.A. (2001) Rapid Urbanisation and Living Arrangements of Older Persons in Africa. In: United Nations, Population Division. Living Arrangements of Older Persons: Critical Issues and Policy Responses. Population Bulletin of the United Nations, Special Issues 42 and $43,288-310$.

[2] Kimuna, S.R (2006) Living Arrangements and Conditions of Older People in Zimbabwe. African Population Studies, 20, 146-163. 
[3] Samson, M. (2009) The Impact of Social Transfers on Growth, Development, Poverty and Inequality in Developing Countries. In: Building Decent Societies, Palgrave Macmillan, UK, 122-150. http://dx.doi.org/10.1057/9780230251052 6

[4] Kakwani, N. and Subbarao, K. (2005) Ageing and Poverty in Africa and the Role of Social Pensions. United Nations Development Programme, International Poverty Centre, Washington DC.

[5] Zimmer, Z. and Dayton, J. (2003) The Living Arrangements of Older Adults in Sub-Sahara Africa in Times of HIV/AIDS. Population Council No. 169.

[6] Sokotovsky, J. (2001) Living Arrangements of Older Persons and Family Support in Less Developed Countries. Population Bulletin of the United Nations, 42/53, 162-192.

[7] Cecilia, T., Glaser, K., Wolf, D.A., van Groenou, M.I.B. and Grundy, E. (2004) Living Arrangements among Older People: An Overview of Trends in Europe and the USA. Population Trends, 115, 24-34.

[8] Palloni, A. (2001) Living Arrangements of Older Persons. In: United Nations Living Arrangements of Older Persons. Critical Issues and Policy Responses. Population Bulletin of the United Nations, Special Issue Nos. 42/43, United Nations, New York, 54-110.

[9] Bongaarts, J. and Zimmer, Z. (2002) Living Arrangements of Older Adults in the Developing World: An Analysis of Demographic and Health Survey, Household Surveys. Journal of Gerontology: Social Sciences, 57B, 5145-5157.

[10] Bösl, A. and Diescho, J. (Eds.) (2009) Human Rights in Africa: Legal Perspectives on Their Protection and Promotion. Macmillan Education, Windhoek.

[11] Wandera, O.S., Ntozi, J. and Kwagala, B. (2014) Prevalence and Correlates of Disability among Older Ugandans: Evidence from the Uganda National Household Survey. Global Health Action, 7, 25686 http://dx.doi.org/10.3402/gha.v7.25686

[12] Payne, C.F., Mkandawire, J. and Kohler, H.P. (2013) Disability Transitions and Health Expectancies among Adults 45 Years and Older in Malawi: A Cohort-Based Model. PLoS Medicine, 10, e1001435. http://dx.doi.org/10.1371/journal.pmed.1001435

[13] Nyirenda, M., Chatterji, S., Falkingham, J., Mutevedzi, P., Hosegood, V., Evandrou, M., Kowal, P. and Newell, M.L. (2012) An Investigation of Factors Associated with the Health and Well-Being of HIV-Infected or HIV-Affected Older People in Rural South Africa. BMC Public Health, 12, 259. http://dx.doi.org/10.1186/1471-2458-12-259

[14] Hairi, N.N., Bulgiba, A., Cumming, R.G., Naganathan, V. and Mudla, I. (2010) Prevalence and Correlates of Physical Disability and Functional Limitation among Community Dwelling Older People in Rural Malaysia, a Middle Income Country. BMC Public Health, 10, 492. http://dx.doi.org/10.1186/1471-2458-10-492

[15] Ng, T.P., Niti, M., Chiam, P.C. and Kua, E.H. (2006) Prevalence and Correlates of Functional Disability in Multiethnic Elderly Singaporeans. Journal of the American Geriatrics Society, 54, 21-29. http://dx.doi.org/10.1111/j.1532-5415.2005.00533.x

[16] Ostchega, Y., Harris, T.B., Hirsch, R., Parsons, V.L. and Kington, R. (2000) The Prevalence of Functional Limitations and Disability in Older Persons in the US: Data from the National Health and Nutrition Examination Survey III. Journal of the American Geriatrics Society, 48, 1132-1135. http://dx.doi.org/10.1111/j.1532-5415.2000.tb04791.x

[17] Ministry of Agriculture, Water and Forestry of Namibia (2009) Namibia Sanitation Situational Analysis Report. Republic of Namibia, Windhoek.

[18] Ministry of Agriculture, Water and Forestry of Namibia (2008) Water Supply and Sanitation Policy. Windhoek. 
[19] Longdon, A.R., Paddick, S.-M. and Walker, R.W. (2012) The Prevalence of Disability in Older People in Hai, Tanzania. Age and Ageing, 41, 517-523.

http://dx.doi.org/10.1093/ageing/afs054

[20] Fitaw, Y. and Boersma, J.M. (2006) Prevalence and Impact of Disability in North-Western Ethiopia. Disability and Rehabilitation, 28, 949-953.

http://dx.doi.org/10.1080/09638280500404552

Submit or recommend next manuscript to SCIRP and we will provide best service for you:

Accepting pre-submission inquiries through Email, Facebook, LinkedIn, Twitter, etc. A wide selection of journals (inclusive of 9 subjects, more than 200 journals)

Providing 24-hour high-quality service

User-friendly online submission system

Fair and swift peer-review system

Efficient typesetting and proofreading procedure

Display of the result of downloads and visits, as well as the number of cited articles

Maximum dissemination of your research work

Submit your manuscript at: http://papersubmission.scirp.org/ 